\title{
A inclusão de crianças em situação de imigrantes na educação infantil de Porto Alegre - RS
}

Jeruza Santos Nobre ${ }^{1}$ Joseane Frassoni dos Santos ${ }^{2}$ Cláudia Rodrigues de Freitas ${ }^{3}$

\begin{abstract}
Resumo:
O Brasil é um país constituído das e pelas imigrações, recebendo destaque na última década, aquelas provenientes do Sul Global, como Haiti e Venezuela. Considerando a chegada de crianças pequenas que possuem uma diferença na forma de comunicação em virtude das imigrações, o presente estudo objetivou prospectar e analisar os números referentes à matrícula de crianças pequenas em situação de imigrante no município de Porto Alegre, RS, direcionando o olhar à educação infantil. Como referencial sobre as imigrações, destacam-se Bulla et al. (2017; 2019), Silva et al. (2018), Pereira (2014; 2019), e, na educação infantil, Barbosa (2010). É notável que, no Brasil, crianças, independentemente de sua origem e de sua situação jurídica, possuem direito de acesso igualitário à educação pública. A prospecção de dados ocorreu por meio dos Microdados disponibilizados pelo Censo Escolar (2019; 2020), o que se constituiu como disparador fundamental para o processo metodológico a fim de analisarmos como vem ocorrendo a inserção das crianças em situação de imigrantes no contexto escolar estudado. As análises apontam o alto número de matrículas em escolas privadas comunitárias e uma nova tendência em 2020 , haja vista o crescimento do número de matrículas de crianças venezuelanas em relação a 2019.
\end{abstract}

\section{Palavras-chave:}

Imigração. Educação infantil. Inclusão escolar. Matrículas.

\footnotetext{
1 Mestranda em Educação no Programa de Pós-Graduação em Educação da Universidade Federal do Rio Grande do Sul. Bolsista CNPq. Integrante do Núcleo de Estudos em Políticas de Inclusão Escolar da Universidade Federal do Rio Grande do Sul. Professora na Rede Municipal de Ensino de Gravataí. E-mail: jeruzanobre76@gmail.com. ORCID id: http://orcid.org/0000-0003-1827-9348. 2 Doutoranda em Educação no Programa de Pós-Graduação em Educação da Universidade Federal do Rio Grande do Sul. Integrante do Núcleo de Estudos em Políticas de Inclusão Escolar da Universidade Federal do Rio Grande do Sul. Supervisora Educacional na Rede Municipal de Ensino de Porto Alegre. E-mail: jfrassoni@hotmail.com. ORCID id: http://orcid.org/00000003-0778-4162.

3 Doutora em Educação pelo Programa de Pós-Graduação em Educação da Universidade Federal do Rio Grande do Sul. Professora na Faculdade de Educação e no Programa de Pós-Graduação em Educação da Universidade Federal do Rio Grande do Sul. E-mail: freitascrd@gmail.com. ORCID iD: https://orcid.org/0000-0002-7105-8539.
} 


\section{The inclusion of immigrant children in early childhood education in Porto Alegre - RS}

\section{Abstract:}

Brazil is a country made up of and by immigration, with a highlight, in the last decade, of immigrants from the Global South, such as Haiti and Venezuela. Considering the arrival of young children who have a differencein the form of communication due to immigration, this study aimed to prospect and analyze the numbers related to the enrollment of young children in immigrant situation in the city of Porto Alegre, RS, directing the look at Early Childhood Education. Our reference on immigration is based on Bulla et al. (2017; 2019), Silva et al. (2018), Pereira (2014; 2019), and on Barbosa (2010), for Early Childhood Education. It is notable that, in Brazil, children, regardless of their origin and legal status, have the right of equal access to public education. Data prospecting was based on microdata provided by the School Census (2019; 2020), which comprised a fundamental trigger for the methodological process in order to analyze how the insertion of immigrant children has occurred in the studied school context. The analyzes show the high number of enrollments in private community schools and a new trend in 2020, given the growth in the number of enrollments of Venezuelan children, when compared to 2019.

\section{Keywords:}

Immigration. Child education. School inclusion. School enrollment.

\section{Inclusión de la niñez inmigrante en la educación infantil en Porto Alegre - RS}

\section{Resumen:}

Brasil es un país constituido de y por las inmigraciones, destacando, en la última década, aquellas provenientes del Sur Global como Haití y Venezuela. Considerando la llegada de niños pequeños que poseen una diferencia en la forma de comunicación debido a las inmigraciones; este estudio tuvo como objetivo analizar los números referentes a la matrícula de niños pequeños en condición de inmigrantes en el municipio de Porto Alegre, RS, centrándose en la Educación Infantil. Como referencia sobre inmigraciones, destacamos a Bulla et al. (2017; 2019), Silva et al. (2018), Pereira (2014; 2019) y, en la Educación Infantil, Barbosa (2010). Cabe señalar que, en Brasil, los niños sin importar su origen y estatus legal, tienen igual derecho de acceso a la educación pública. La prospección de datos se realizó a través de microdatos ofrecidos por el Censo Escolar (2019-2020), que constituyó un aspecto fundamental del proceso metodológico, permitiendo analizar cómo se ha producido la inserción de niños en situación de inmigrantes en el contexto escolar estudiado. El análisis muestra un alto número de matrículas en escuelas privadas comunitarias y una nueva tendencia en 2020 debido al crecimiento del número de matrículas de niños venezolanos en relación a 2019.

Palabras clave:

Inmigración. Educación infantil. Inclusión escolar. Matrículas.

\section{Introdução}

Os outros passam a escrita a limpo. Eu passo a escrita a sujo. Como os rios que se lavam em encardidas águas. Os outros têm caligrafia, eu tenho sotaque. O sotaque da terra (COUTO, 2006, p. 232). 
O escritor moçambicano Mia Couto nos inspira a pensar sobre as singularidades do existir humano quando se refere ao sotaque da terra. Brasileiros, argentinos, haitianos, venezuelanos e tantas outras nacionalidades, através de suas culturas, de suas línguas, vão tecendo seus modos de existir e de intervir no mundo do mesmo modo que o mundo influencia em sua história e sua trajetória de vida. Imigrar não implica apenas se encaixar em seu novo território, mas agir nele e, assim, levar um pouco de si à nova localidade. Partindo desse pressuposto, é possível pensar nos diferentes sotaques que compõem o sotaque da Terra a partir da compreensão da singularidade imersa em um contexto plural, no qual todos os sujeitos estão interconectados.

Por meio dessa breve reflexão, trazemos à discussão o processo de imigração com enfoque para as crianças pequenas da educação infantil, considerando que a diferença na forma de comunicação requer a eliminação de barreiras para a inclusão dessas crianças nas instituições infantis e a proposição de práticas pedagógicas adequadas a elas (BRASIL, 2009). Essa escolha se efetiva em virtude da trajetória docente de duas das três autoras deste estudo ao verificarem a matrícula de crianças em situação de imigrantes nas instituições onde atuam, especificamente, na rede municipal de ensino de Porto Alegre, RS.

Com o ingresso das crianças provindas do Haiti e da Venezuela, percebemos a necessidade do acolhimento delas nas instituições de educação infantil, que recebe crianças de zero a seis anos. Sendo assim, é nesses espaços que se dá seu primeiro contato com a educação, considerando os aspectos culturais e linguísticos. A especificidade da etapa na qual as crianças são matriculadas também se caracteriza como um aspecto importante, especialmente quando nos referimos à educação infantil, ou melhor, primeira etapa da educação básica, que possui uma especificidade nas práticas pedagógicas para as crianças pequenas, haja vista objetivar que se desenvolvam de forma integral (BRASIL, 1996) por meio de ações pedagógicas pautadas na indissociabilidade entre o cuidar e o educar.

Considerando esses aspectos associados ao entendimento de que a infância é afirmada como "[...] uma categoria geracional, social e histórica e geograficamente construída, heterogênea, atravessada pelas variáveis de gênero, classe, religião e etnia” (BARBOSA, 2010, p. 1), a inserção da criança pequena em situação de imigrante requer premência de estudo. Nesse sentido, é primordial a atenção direcionada às infâncias na sua pluralidade, as quais carregam na sua constituição "[...] uma experiência social e pessoal, ativamente construída e permanentemente ressignificada" (BARBOSA, 2007, p. 1065).

Dessa forma, este estudo objetiva prospectar e analisar os números referentes à matrícula de crianças pequenas em situação de imigrantes no município de Porto Alegre, RS, direcionando o olhar à etapa da educação infantil e às nuances envolvidas na chamada imigração de crise, que, como será explicada no decorrer do trabalho, é a imigração decorrente de causas além da vontade do sujeito. Adotamos o termo 'em situação de imigrante' por compreendermos que essa é a situação atual vivida pelo sujeito, ele não é o imigrante, mas está vivendo a imigração.

É importante lembrar que o Brasil é um país constituído das e pelas imigrações (SILVA et al., 2018), as quais, quando ocorriam em sentido norte/sul (países europeus, na maioria colonizadores, para países que foram colônias), eram vistas como movimento de prosperidade, mas quando as rotas migratórias passaram a ocorrer no sentido sul para o norte, as imigrações passaram a ser vistas como um problema, sendo categorizadas como imigrações involuntárias (PEREIRA, 2014) ou imigrações de crise (PEREIRA, 2019).

Em Porto Alegre, RS, o processo migratório mostra-se intenso. É possível observar, ao andar pelas ruas, pelo centro ou pelo mercado público, a existência de muitos idiomas e cores trazendo sons a um país tecido por culturas e línguas diversas. Entendendo que as infâncias precisam ser respeitadas, um aspecto importante é a escolarização dessas crianças em situação de imigrante. A educação como direito de todos prevista na Constituição Federal de 1988 (BRASIL, 1988) e reafirmada na Lei no 9.394, de vinte de dezembro de 1996 (BRASIL, 1996), garante que as crianças em situação de imigrantes possam ingressar na escola em condições de igualdade de acesso e perma- 
nência, o que volta a ser afirmado na Lei $\mathrm{n}^{\circ}$ 13.445, de 24 de maio de 2017 (BRASIL, 2017). Vale destacar que, além de todas as peculiaridades envolvidas no ser criança, ela ainda tem que lidar com novos desafios de adaptação nesse novo contexto que nem sempre está preparado para recebê-la.

Como pesquisadoras que têm como premissa a inclusão para todos, consideramos a importância de focarmos nossas ações para a eliminação das barreiras que os imigrantes encontram no seu processo de escolarização no país no qual ingressam, como a língua e o encontro com uma nova cultura. Esse aspecto também vem sendo enfatizado nas ações junto às pessoas com deficiência, previsto no Decreto no 6.949, de 25 de agosto de 2009 (BRASIL, 2009). A ênfase para a faixa etária das crianças matriculadas na educação infantil relaciona-se à identificação da existência de maior investimento em investigações sobre o tema no contexto de São Paulo: Norões (2018; 2021), Nascimento e Morais (2021), Waldman e Breitenvieser (2021), requerendo, assim, a premência de investigação em outros contextos, como o de Porto Alegre.

\section{Um "novo" sotaque: as imigrações}

A diferença entre migrante, imigrante e emigrante é amplamente abordada nos bancos escolares, no entanto, as explicações são simplistas. Encontramos em Umberto Eco uma distinção qualificada entre os conceitos, a qual nos propicia compreender a imigração como um processo,

[...] onde os fenômenos migratórios podem ser controlados politicamente, limitadamente, incentivados, planejados ou aceitos... Migração seja violenta ou pacífica, é como um fenômeno natural, ocorre e ninguém pode controlá-lo. Existe 'migração' quando uma população inteira, pouco a pouco, passa de um território para outro. (ECO, 2019, p. 20, tradução nossa).

O que emerge, então, é que na imigração há um fator político, um controle, uma limitação dos fluxos migratórios que se dá a partir do pressuposto da nacionalidade, do estado-nação e da soberania, a qual, muitas vezes, impede a entrada de estrangeiros e define o tratamento dado a eles. Dá-se, dessa maneira, uma distinção nas classificações que referem o sujeito em situação de imigrante como imigrante, estrangeiro, refugiado, entre outras.

\section{Imigração de crise e refúgio}

Há discussões sobre o uso dos conceitos a respeito dos movimentos que envolvem a imigração de crise, ou também conceituada como imigração involuntária ou forçada, pois, ao contrário da voluntária, ocorre não pela vontade do indivíduo, mas por forças alheias ao seu desejo, como a fome, crises econômicas, sociais e políticas, grave violação dos direitos humanos, entre outros fatores (PEREIRA, 2014).

Sendo assim, "[...] são considerados imigrantes forçados todos os sujeitos que, por motivos alheios ao seu desejo, vontade ou interesse, são obrigados a deixarem o seu local de moradia habitual" (PEREIRA, 2019, p. 26). Esse tipo de imigração passa a ser vista em países que sofrem crises econômicas, políticas, sociais ou ambientais (MAGALHÃES, 2019). A partir disso, mobilizados por essas circunstâncias, os imigrantes abandonam tudo o que têm, até mesmo suas famílias e buscam oportunidades ingressando em um novo país (PEREIRA, 2019). Muitas vezes, esses sujeitos classificam-se com o status de refugiados.

Os sujeitos em situação de refúgio são pessoas que, independentemente de sua vontade, foram obrigadas a deixar seu país, normalmente por motivos de ordem econômica, ambiental, originários de guerras civis ou demais conflitos e perseguições internas. São sujeitos que tiveram de deixar seus lares e solicitar proteção externa para se manterem vivos (PEREIRA, 2014). 
Além da Convenção Relativa ao Estatuto dos Refugiados, existe também a Declaração de Cartagena (1984). Segundo Bulla et al. (2017), “A lei brasileira 'adota parcialmente a Declaração de Cartagena' (ACNUR, 2013) e cria o Comitê Nacional de Refugiados (CONARE), que determina as condições de elegibilidade para os pedidos de refúgio" (BULLA et al., 2017, p. 4). O Alto Comissariado das Nações Unidas - ACNUR - defende, nesse ponto, que os refugiados não são imigrantes e que nomeá-los dessa forma poderia ocasionar uma confusão, podendo, inclusive, afetar a proteção a eles. Salientamos que esta pesquisa corrobora essa definição, pois, ao assumirem a classificação de refugiados, esses sujeitos possuem proteções internacionais, que incluem sua não devolução ao país de origem.

Destaca-se que algumas pesquisas optam pela nomenclatura imigração forçada ou imigração involuntária (BEZERRA; BORGES; CUNHA, 2020; WEIß, 2018; PEREIRA, 2014; 2019), ao se referirem ao sujeito em situação de refúgio, entendendo que, assim, a abrangência da proteção representaria melhor a sua necessidade. Como no caso dos imigrantes vindos do Haiti e da Venezuela, por muitas vezes não se enquadrarem na classificação necessária para o status de refúgio, recebem apenas o visto por razões humanitárias, o que não lhes garante as mesmas proteções. Dessa forma, eles não são apenas imigrantes que decidiram viver no Brasil, mas pessoas que, por necessidades alheias à sua vontade, tiveram de deixar seu país, porém, para a legislação vigente, são vistos da mesma forma que os sujeitos que imigraram por força da própria vontade.

Conforme dados do Alto Comissariado das Nações Unidas (ACNUR, 2020), há cerca de 79.5 milhões de pessoas em situação de deslocamento forçado pelo mundo, e o Brasil se configura como um dos principais destinos desses imigrantes que buscam meios de viver, trabalhar e estudar no novo território. Aspectos que são garantidos pela Declaração Universal dos Direitos Humanos (1948), pela Convenção Relativa ao Estatuto do Refugiado (ACNUR, 1951) e pela Lei no 13.445, de 24 de maio de 2017 que institui a Lei de Migração (BRASIL, 2017).

Outro aspecto que diferencia o imigrante de crise de outros é o olhar da população brasileira para esse sujeito. Isso ocorre em virtude do entendimento de que os imigrantes do Sul Global prejudicam o novo país, enquanto a imigração de pessoas vindas do Norte para o Sul é entendida como uma entrada de riquezas e mão de obra qualificada (MUHR; AZEVEDO, 2019). Isso advém da crença de que imigrantes vindos da Europa e dos Estados Unidos seriam consumidores, estudiosos e investidores em potencial para o novo território (PEREIRA, 2019), enquanto aqueles vindos da América do Sul e das demais regiões tidas como subdesenvolvidas viriam sem estudos e com necessidade de ajuda financeira (MUHR; AZEVEDO, 2019), dessa forma 'roubando' os empregos brasileiros e inflando o serviço público, já esgotado.

É interessante salientarmos que isso não condiz com a verdade, pois, segundo dados do ACNUR (2020) e de CAVALCANTI et al. (2018), a maioria dos imigrantes vindos desses países é de pessoas com nível de escolaridade alto como graduação ou até mesmo pós-graduação concluídas em seu país de origem, pois acabam sendo essas as pessoas que conseguem emigrar.

\section{Metodologia}

Este estudo é parte de uma pesquisa maior, e, para este artigo, temos por objetivo prospectar e analisar os números referentes a matrículas de crianças pequenas em situação de imigrantes no município de Porto Alegre, RS, direcionando o olhar à etapa da educação infantil e à conhecida imigração de crise. A primeira vez que a expressão criança em situação de imigrante foi usada tem relação na compreensão de que a imigração é a situação atual vivida pela criança, que também a constitui, mas não a reduz a esse termo. Podemos dizer que estão em situação de imigrante, porém não integram o povo imigrante, como se suas características particulares fossem dissolvidas dentro do termo povo. Conforme Agamben (2004), 
Toda interpretação do significado do termo 'povo' deve partir do fato singular de que, nas línguas europeias modernas, ele sempre indica também os pobres, os deserdados, os excluídos. Um mesmo termo denomina, assim, tanto o sujeito político constitutivo quanto a classe que, de fato, senão de direito, é excluída da política. (AGAMBEN, 2004, p. 183).

O referencial teórico que sustenta o conceito de imigração referenda-se em Resstel (2015), Bulla (2017), Pereira (2014; 2019), Eco (2019), além de Figueredo, Zanellato (2017); Lia, Radunz (2016); e, Sarriera, Pizzinato, Meneses (2005), que concordam quanto à compreensão de como se deu o processo de imigração no Brasil, no Rio Grande do Sul e em Porto Alegre. Sobre o conceito de infâncias, tem-se Barbosa (2007).

A fim de compreender o contexto e a intensidade dos processos de escolarização de crianças em situação de imigrantes em Porto Alegre, RS, buscou-se prospectar e analisar o número de matrículas dessas crianças através dos Microdados do Censo Escolar $(2019 ; 2020)$, os quais foram prospectados por meio do programa estatístico SPSS (Statistical Package for the Social Sciences). A identificação dos locais de origem dessas crianças também se realizou com o intuito de conhecermos de forma mais minuciosa, a partir da procedência, o leque cultural, as línguas e os demais elementos que constituem hoje em dia as escolas do município de Porto Alegre.

\section{Crianças em situação de imigrantes no município de Porto Alegre - RS: o ingresso na educação infantil}

O município de Porto Alegre, capital do estado do Rio Grande do Sul, possui uma população de 1.488.252 (BRASIL, 2020), sendo 8.845 (BRASIL, 2010) sujeitos vindos de países estrangeiros. Sem estatísticas mais atuais, o que impacta as análises, pois, na última década, segundo Cavalcanti, Oliveira e Macedo (2020), o ingresso de sujeitos em situação de imigrantes, na região sul do Brasil, representou 22\% (142.216) no cenário migratório brasileiro, sendo 45.967 pessoas adentrando o estado do Rio Grande do Sul. Apesar de os dados (CAVALCANTI; OLIVEIRA; MACEDO, 2020) apontarem que a maioria dos sujeitos que ingressam no País é composta por homens em idade de trabalho e com níveis médios ou superiores de ensino, esses, muitas vezes, vêm acompanhados de suas famílias ou, depois de algum tempo em solo brasileiro, enviam recursos para que suas famílias venham ao seu encontro (BULLA, 2017).

Referente às crianças em deslocamentos, dados do ACNUR (2020) mostram que 40\% das pessoas em situação de imigração de crise são crianças, representando um total de trinta milhões a 34 milhões. Tal realidade pode comprovar-se por meio do número de matrículas de crianças em situação de imigrante no ensino brasileiro, desafiando-nos com novas e diferentes culturas, idiomas, sotaques dentro da escola, reforçando o objetivo desta pesquisa.

A criança imigrante traz consigo muitas histórias, mas nem sempre de fácil leitura. Identificamos composições que nos dizem de classificações, proteções, perda de direitos e de luta antes mesmo de entender os significados que a palavra imigração comporta. Além de criança, é também um sujeito que vivenciou a imigração e todas as intensidades que isso acarreta (MARTUSCELLI, 2014). Considerando esse aspecto, a atenção dada às crianças imigrantes se faz primordial, pois carregam uma forma singular e, ao mesmo tempo, plural de se manifestar no mundo e isso não deve ser impedido através de classificações e de legislações.

O município de Porto Alegre, RS, conta com 35 escolas municipais de educação infantil (atendimento em turno integral), sete escolas municipais de educação infantil/jardins de praça (atendimento em meio turno), 35 escolas municipais de ensino fundamental com turmas de pré-escola, 220 instituições de educação infantil conveniadas à Prefeitura Municipal de Porto Alegre (PMPA) e 364 escolas de educação infantil privadas (PORTO ALEGRE, 2021a). 
No tocante à elaboração de legislação que institua ações para as pessoas em situação de imigrantes, o município dispõe do Decreto no 18.815, de dez de outubro de 2014 (PORTO ALEGRE, 2014), o qual prevê, no art. $2^{\circ}$, as atribuições do Comitê Municipal de Atenção às Pessoas Imigrantes, Refugiadas, Apátridas e Vítimas do Tráfico de Pessoas no Município de Porto Alegre, sendo a Secretaria Municipal de Educação uma das representantes.

A seguir, apresentamos, por meio do primeiro gráfico, os dados de matrículas de crianças em situação de imigrantes na etapa da educação infantil nas quatro esferas administrativas: federal, estadual, municipal e privada. O segundo gráfico traz os dados da rede privada a fim de analisarmos detalhadamente a matrícula nessa esfera administrativa.

Gráfico 1: Matrícula de estrangeiros na educação infantil (creche e pré-escola) $(2019 ; 2020)$

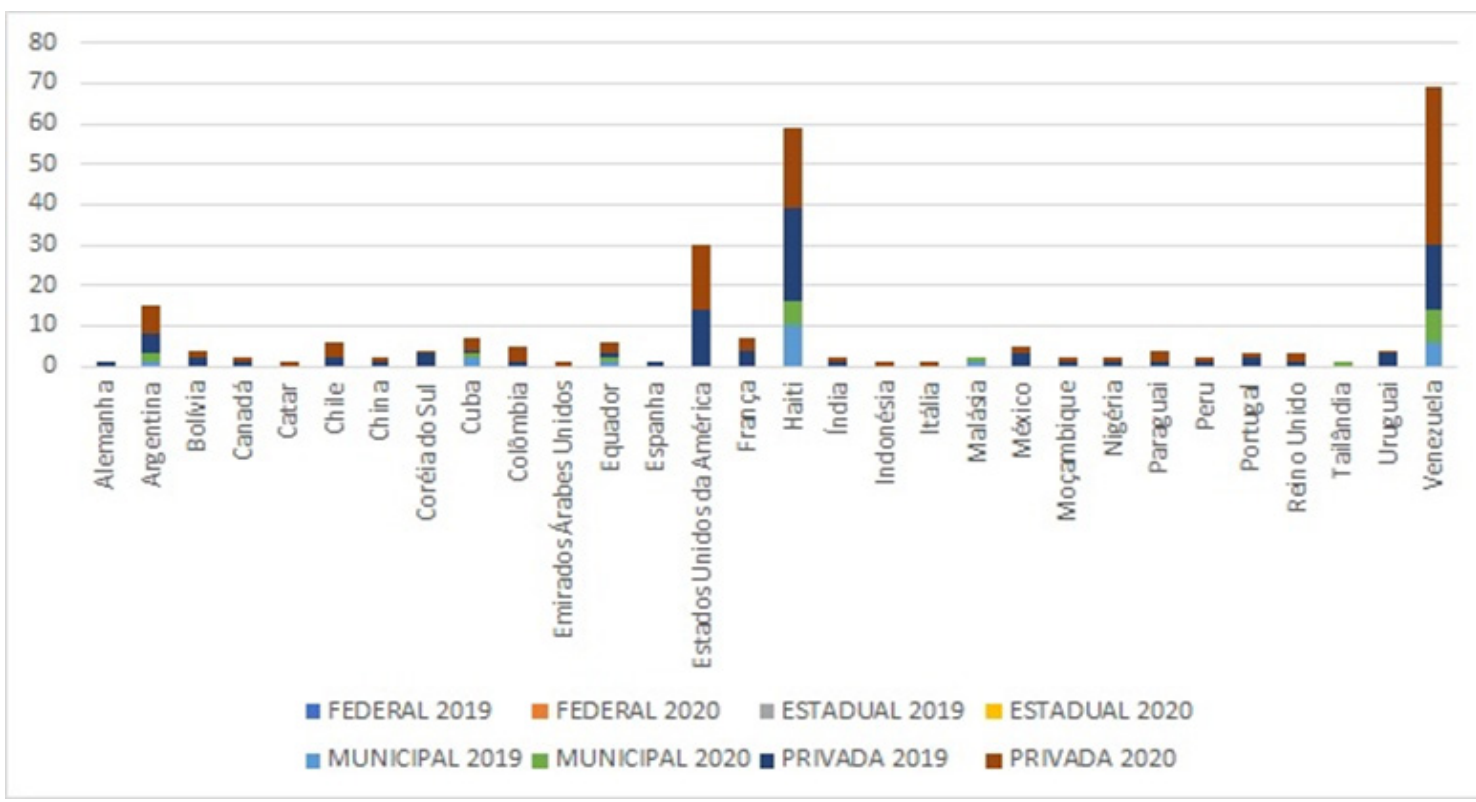

Fonte: Elaborado pelas autoras.

Gráfico 2: Matrícula de estrangeiros na educação infantil (creche e pré-escola) $(2019 ; 2020)$ na rede privada

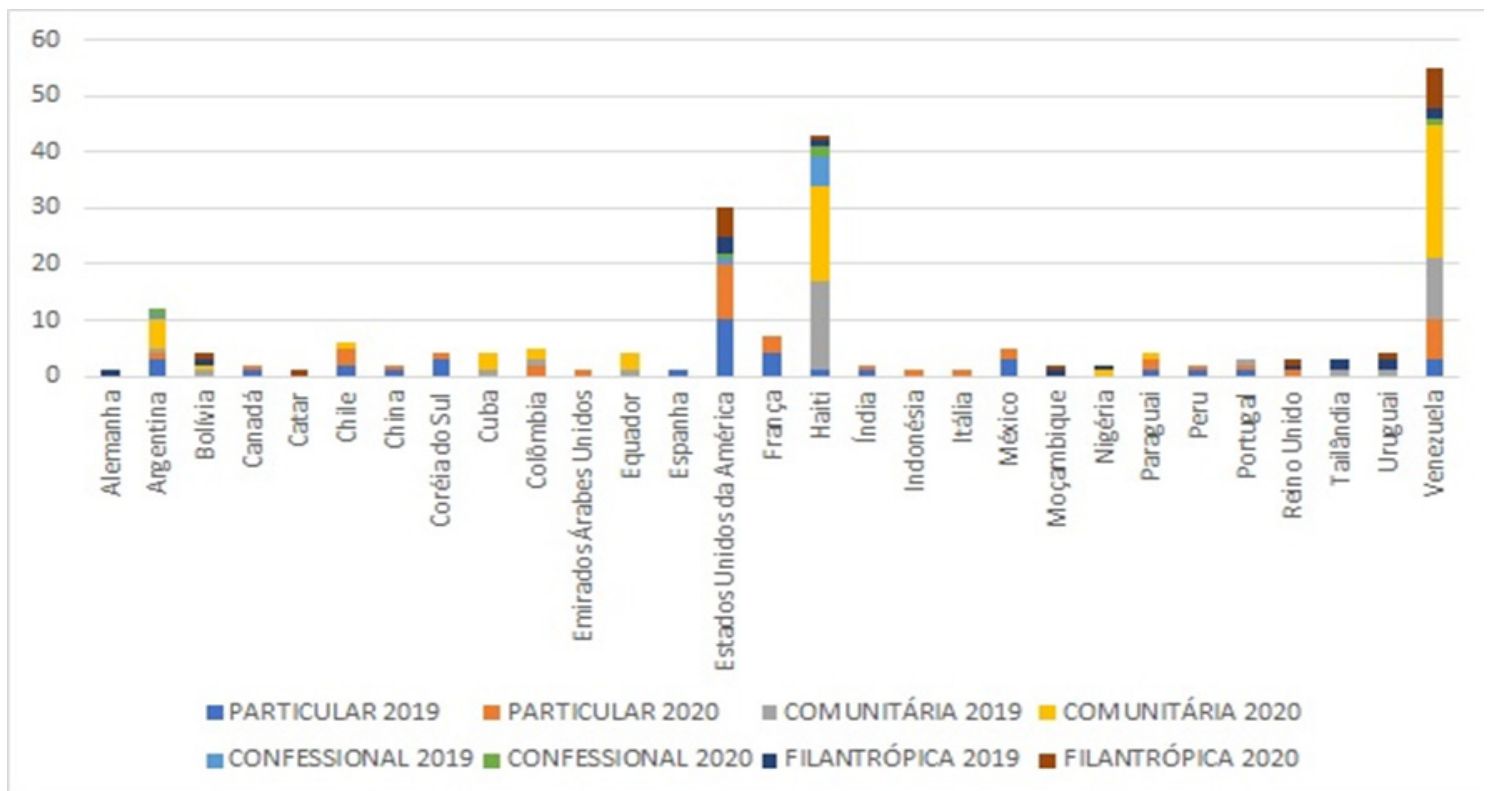

Fonte: Elaborado pelas autoras. 
Os dados apontam o maior número de matrículas dessas crianças na rede privada do município seguido da rede municipal de ensino. $\mathrm{O}$ maior índice na rede privada nos remete à necessidade de análise da categoria dessas escolas. Conforme sugerem os dados, o maior número de matrículas se verifica na rede privada comunitária, conhecida popularmente como 'escola conveniada', ou melhor, instituição que firma parceria com a prefeitura para receber crianças que deveriam estar matriculadas nas instituições de educação infantil da rede municipal de ensino. Em virtude da alta demanda de matrículas nessa faixa etária, principalmente em relação à creche, que, atualmente, tem demanda reprimida de 3.337 vagas (PORTO ALEGRE, 2021b), as gestões do município de 2016-2020 e a atual gestão 2021-2024 têm optado por essa parceria ao invés de investir na criação de instituições infantis da própria rede.

Outro aspecto importante da rede privada comunitária relaciona-se ao maior índice de matrículas de crianças, durante o ano de 2019, do Haiti, seguido da Venezuela. Diversos fatores estimulam o ingresso de haitianos no Brasil, dentre eles está o terremoto que atingiu o país caribenho em 2010, destruindo a cidade de Porto Príncipe e sendo responsável pela morte de 316.000 pessoas.

Conforme Bulla et al., "[...] o desastre intensificou o fenômeno da diáspora haitiana, e o Brasil, pela sua forte presença no país, passou a ser uma das rotas principais" (BULLA et al., 2017, p. 5). Porém, o desastre ambiental não foi a única causa da imigração haitiana. Nesse país, ocorre uma tradição da diáspora em que famílias inteiras juntam recursos para que um dos filhos consiga emigrar e, dessa forma, enviar dinheiro e mandar buscar seus familiares que lá ficaram. Todavia, essa tradição envolve nunca cortar laços com seu local de origem, sendo comum o compatriota voltar ao Haiti para visitas e até mesmo manter uma moradia lá (HANDERSON, 2015). A viabilidade de imigração se intensificou em 2010, dada a facilidade de acesso ao Brasil, que se tornou parte da rota da imigração, embora essa prática já se verificasse no contexto brasileiro.

Desse modo, o termo diáspora é comum no Haiti, designando os irmãos e compatriotas, que deixam seu local de origem, enviam remessas de dinheiro, ou voltam e constroem casa para sua família. Muitas vezes, destinam recursos para que seus familiares e amigos também consigam deixar o país. Não há diáspora se o compatriota não retornar e mostrar seu sucesso com a imigração (volta essa que não pode ser definitiva, caso seja, o compatriota deixa de ser diáspora). Existe, assim, uma expectativa com o retorno do sujeito, o que alimenta, no compatriota que retornará, a vontade e o desejo de mostrar que fora bem-sucedido (HANDERSON, 2015).

Há um ritual de preparação da viagem ao Haiti: compram-se vestidos, tênis, sapatos, perfumes, presentes, além de juntar dinheiro para levar ao país. A viagem de volta é planejada com bastante antecedência. Quando chegam os mais endinheirados alugam um carro de última geração; exibem os vestidos de marca, os cordões de ouro; financiam festas para familiares, amigos e conhecidos, sendo geralmente chamados de gwo diaspora (grande diáspora). (HANDERSON, 2015, p. 63, grifos nossos).

A pessoa diáspora constitui um novo modo de ser para o haitiano, unindo comportamentos de diferentes culturas, roupas e idiomas, sendo comum ver muitos que imigraram para os Estados Unidos, falando palavras em inglês ao retornarem para o Haiti.

Em 2011, a média de ingresso de haitianos no Brasil foi de duzentos e cinquenta (250) indivíduos ao mês, conforme o Conselho Nacional de Imigração (BRASIL, 2011). Em 2012, consolidou-se a Resolução Normativa CNIg nº. 97, de doze de janeiro de 2011 (BRASIL, 2011), que dispõe sobre a permanência de nacionais haitianos através do visto permanente expedido por razões humanitárias, mas que limitava o acesso a cem (100) haitianos por mês, gerando filas que aumentavam cada dia mais. Em 2013, observando o grande número de pessoas aguardando, as restrições foram retiradas e os casos passaram a ser avaliados um a um (FERNANDES; FARIA, 2017). 
Apesar de esse visto por causas humanitárias ter sido pensado, inicialmente, para os sujeitos vindos do Haiti, hoje em dia se estende também às pessoas que atravessam a fronteira Venezuela-Brasil em virtude da situação política da República Bolivariana, a qual impede que esses sujeitos retornem à Venezuela. Por esses fatores, a nacionalidade venezuelana acaba sendo bastante vista nos números de estrangeiros, ingressando no Brasil. Conforme dados da Operação Acolhida, desde abril de 2018 até janeiro de 2020, foram interiorizadas mais de trinta mil pessoas para mais de quatrocentas cidades brasileiras em diversas Unidades da Federação, sendo que o Rio Grande do Sul recebeu 6.848 venezuelanos e Porto Alegre, 1.868, tornando-se o quinto município brasileiro com maior número de sujeitos vindos da Venezuela (BRASIL, 2021).

Dentre as esferas administrativas, a rede municipal é a segunda com maior número de matrículas, o que caracteriza nossa observação em relação à entrada de crianças haitianas e venezuelanas no contexto em análise. A rede federal e a estadual não apresentam nenhuma matrícula de crianças em situação de imigrantes na etapa estudada.

Em 2020, o número de matrículas continua sendo maior na rede privada comunitária, no entanto, o país com maior índice é a Venezuela, demonstrando uma nova tendência em relação ao ano de 2019. A rede municipal permanece sendo a segunda dependência administrativa com maior número de matrículas depois da rede privada. As redes federal e estadual, em 2020, seguem não apresentando matrícula na etapa estudada.

Esses dados trazem importantes evidências em relação ao acesso às escolas de crianças em situação de imigrante na cidade de Porto Alegre e os estudos que demonstram uma alta migratória nos anos de 2018 e 2019 referente ao ingresso de venezuelanos no Brasil (BARBOSA; JESUS; GIUDICE, 2021). Essa imigração se deve pela crise econômica, política e humanitária a assolar a Venezuela, país que faz fronteira com a região norte do Brasil.

[...] detentora da maior reserva de petróleo do mundo desde meados de 2013, enfrenta os reflexos da queda do preço do petróleo que a colocou em situação de vulnerabilidade. Crise está agravada pelas políticas autoritárias do governo de Nicolás Maduro, e pelo boicote dos EUA (BARBOSA; JESUS; GIUDICE, 2021, p. 119).

Com a queda do preço do petróleo e o boicote dos Estados Unidos, a Venezuela, que comprava muitos produtos de outros países e mantinha sua economia na venda de barris, vê-se em crise econômica, sendo esse um fator que gera: desemprego, aumento da inflação, escassez de recursos básicos e aumento da violência (JESUS; GIUDICE, 2021). Pela facilidade de acesso ao Brasil, fronteira terrestre e, em virtude da não necessidade de passaporte, muitos venezuelanos optam pela travessia mesmo sem terem dimensão da distância em quilômetros e em dias até chegar à sede da Polícia Federal brasileira. Movidos apenas pela esperança, iniciam a travessia e seu movimento de ingresso no Brasil.

Conforme Garcia (2015, p. 1), “[...] a terra onde se nasce é a infância [...]”, e abandonar a infância é muito penoso, não só para os imigrantes como também para seus filhos. Muitas vezes, essas crianças são forçadas a deixarem seus amigos, lares, familiares e sua escola, vivendo uma relação dicotômica da sua própria imigração e da imigração de seus pais e responsáveis que também estão imersos nesse processo (ASSUMPÇÃO; AGUIAR, 2019). Além desses aspectos, é fundamental atentarmos não somente para a eliminação das barreiras que impedem a plena participação das crianças no contexto educacional, mas também no contexto de vida, pois a chegada a um novo país pode ser um processo árduo, já que implica aprender um novo idioma e a adaptação a uma cultura distinta da sua (UNICEF, 2021).

Ao analisarmos os dados das matrículas e observarmos o ingresso de crianças vindas do Haiti e da Venezuela, a palavra acolhimento toma novos sentidos. Essa imigração não é simples, envolve questões muito delicadas como brigas econômicas, guerra de poder e crises políticas. 
As crianças, nesse cenário, estão à mercê do efeito de decisões das quais muitos adultos não têm compreensão. Apesar da existência de ampla legislação que vai desde a Constituição Federal de 1988 até tratados internacionais e a Lei de Migração (2017), ainda não existem políticas públicas que efetivem a garantia dos direitos das crianças em situação de imigrantes, principalmente considerando os "[...] fatores idade ou fase de vida" (NORÕES, 2021, p. 427).

É notável haver legislações que não chegam ao alcance da população a quem se destinam. Contudo, registramos pequenos movimentos de professoras, ONGs, escolas e até mesmo universidades que visam ao acolhimento, inclusão e efetivação dos direitos desses sujeitos.

\section{Considerações finais}

Como é chegar na escola e não ter material adequado para você? Como é ser uma criança imigrante? Como é viver uma imigração em tenra idade? Como as escolas vêm oferecendo adequações para a inclusão de crianças pequenas oriundas de outros países, especialmente da Venezuela e Haiti? Como a escola vem organizando suas ações para incluir as crianças em situação de imigrante na direção de acolher outras culturas, línguas, crenças e religiões? Como não estigmatizar ou isolar as crianças em situação de imigrante?

Os questionamentos escritos no parágrafo anterior reverberam ao sinalizarmos o ingresso dessas crianças nas instituições educativas de Porto Alegre - RS. Países tão distantes, Venezuela ao lado do Brasil e Haiti na região caribenha, porém com histórias de lutas e de desigualdades tão semelhantes e carregando a esperança de uma vida melhor e de acessos a serviços básicos como saúde e educação, o que serve de força motivadora para realizarem a imigração.

Como os dados demonstram (CAVALCANTI; OLIVEIRA; MACEDO, 2020), a região sul do Brasil se tornou a segunda localidade de maior ingresso dos sujeitos que vivenciam a imigração, sendo a capital gaúcha como um dos pontos de chegada. A última atualização referente aos imigrantes que moram na região foi em 2010, ignorando toda a última década, em que tivemos o aviltamento migratório sentido Sul do mundo, com destaque ao Haiti e à Venezuela, passando a fazer do Brasil parte de sua rota migratória e, com isso, a nova moradia de centenas de sujeitos com histórias únicas. Destaca-se, ainda, mais uma singularidade ao se conceituar imigração, pois a experiência de deixar seu país e ingressar em outro, suas motivações, seus desejos, anseios vão ser diferentes, conforme cada sujeito, mesmo tendo cenários políticos e econômicos semelhantes.

No que se refere ao ingresso das crianças em situação de imigrantes nas instituições educativas, percebemos, assim como na matrícula de crianças porto-alegrenses, a opção das gestões municipais pela oferta de vagas na rede privada comunitária ou conveniada. Isso fica evidente nos dados do gráfico dois, que aponta o aumento de matrículas dessas crianças em escolas comunitárias, inclusive com uma diferença significativa entre os anos de 2019 e 2020 referente à matrícula de crianças haitianas e venezuelanas. Dessa forma, destacamos que os dados sugerem a necessidade de políticas públicas e de ações coletivas que visem ao acolhimento, à inclusão e ao respeito aos direitos dessa coletividade. A partir disso, algumas questões emergem em relação aos dados prospectados: em que condições essas escolas comunitárias atuam? Em que condições recebem crianças que vivenciaram a imigração ainda na primeira infância?

O cuidado com a especificidade da faixa etária é outro aspecto que precisa ser considerado na formulação de políticas públicas para essas crianças, pois, como mencionado anteriormente, a etapa da educação infantil possui delicadezas e não bastam leis que garantam a matrícula, mas fazem-se necessários subsídios a fim de que esse ingresso na instituição educativa se dê com qualidade e equidade de acesso com as demais crianças. Isso vai desde o incentivo público à formação de profissionais sobre a temática até o desenvolvimento de políticas de acesso e de permanência dessas crianças no âmbito escolar. 
Em suma, além do acesso, enfatizamos a importância da permanência da criança em situação de imigrante, haja vista isso perpassar a eliminação de barreiras para sua plena inclusão na instituição de educação infantil. Esse aspecto relaciona-se com a organização e com a proposição de práticas pedagógicas adequadas a essas crianças, desde a utilização de comunicação alternativa e de ações que contemplem a cultura e a pluralidade das infâncias.

\section{Referências}

AGAMBEN, Giorgio. Homo Sacer: o poder soberano e a vida nua. 1. ed. Belo Horizonte: UFMG, 2004.

ALTO COMISSARIADO DAS NAÇÕES UNIDAS PARA REFUGIADOS. Convenção Relativa ao Estatuto dos Refugiados, 1951. Disponível em: http://www.acnur.org/t3/fileadmin/Documentos/portugues/BDL/Convencao_relativa_ao_Estatuto_dos_Refugiados.pdf. Acesso em: 13 maio 2021.

ALTO COMISSARIADO DAS NAÇÕES UNIDAS PARA REFUGIADOS. Declaração de Cartagena, 1984. Disponível em: https://www.acnur.org/fileadmin/Documentos/portugues/BD_Legal/Instrumentos_Internacionais/Declaracao. Acesso em: 13 maio 2021.

ALTO COMISSARIADO DAS NAÇÕES UNIDAS PARA REFUGIADOS. Organização das Nações Unidas (org.). Dados sobre refúgio, 2020. Dados sobre refúgio no Brasil. Disponível em: https://www.acnur.org/portugues/dados-sobre-refugio/. Acesso em: 13 maio 2021.

ASSUMPÇÃO, Adriana Maria; AGUIAR, Gabriela de Azevedo. "Você precisa falar português com seu filho": desafios para o processo de inclusão de crianças imigrantes em escolas do Rio de Janeiro. Revista Iberoamericana de Educación, [S.I.], v. 81, n. 1, p. 167-188, 5 set. 2019. Organizacion de Estados Iberoamericanos. DOI: http://dx.doi.org/10.35362/ rie8113541.

BARBOSA, André Lucas Palma; JESUS, Cíntia Silva de; GIUDICE, Dante Severo. "VIDAS SECAS” VENEZUELANA: uma análise preliminar da diáspora. Revista de Geopolítica, Natal, v. 12, n. 1, p. 118-132, jan. 2021. Disponível em: http://revistageopolitica.com.br/index.php/revistageopolitica/article/download/332/270. Acesso em: 15 maio 2021.

BARBOSA, Maria Carmem Silveira. Pedagogia da infância. In: OLIVEIRA, Dalila Andrade; DUARTE, Adriana Maria Cancella; VIEIRA, Livia Maria Fraga. Dicionário: trabalho, profissão e condição docente. Belo Horizonte: UFMG, Faculdade de Educação, 2010. 1 CD-ROM. Disponível em: https://gestrado.net.br/wp-content/uploads/2020/08/312-1. pdf. Acesso em: 13 maio 2021.

BARBOSA, Maria Carmem Silveira. Culturas escolares, culturas de infância e culturas familiares: as socializações e a escolarização no entretecer destas culturas. Educ. Soc., Campinas, v. 28, n. 100 - Especial, p. 1059-1083, out. 2007. Disponível em: http://www.cedes.unicamp.br. Acesso em: 10 maio 2021.

BEZERRA, Cecília Braga; BORGES, Lucienne Martins; CUNHA, Maiara Pereira. Filhos das fronteiras: revisão de literatura sobre imigração involuntária, infância e saúde mental. Ces Psicología, [S.I.], v. 12, n. 2, p. 26-40, 29 ago. 2020. Universidad CES. DOI: http://dx.doi.org/10.21615/cesp.12.2.3.

BRASIL. Unicef. Assembleia Geral das Nações Unidas (comp.). Declaração Universal dos Direitos Humanos, 1948. Adotada e proclamada pela Assembleia Geral das Nações Unidas (resolução 217 A III) em 10 de dezembro 1948. Disponível em: https://www.unicef.org/brazil/declaracao-universal-dos-direitos-humanos. Acesso em: 15 abr. 2021.

BRASIL. Constituição da República Federativa do Brasil, 05 de outubro de 1988. Brasília, DF: Senado, 1988.

BRASIL. Lei $n^{\circ}$ 9.394, de 20 de dezembro de 1996. Estabelece as diretrizes e bases da educação nacional. Disponível em: http://www.planalto.gov.br/ccivil_03/leis/19394.htm. Acesso em: 5 maio 2021.

BRASIL. Decreto $n^{\circ}$ 6.949, de 25 de agosto de 2009. Promulga a Convenção Internacional sobre os Direitos das Pessoas com Deficiência e seu Protocolo Facultativo, assinados em Nova York, em 30 de março de 2007. Disponível em: http:// www.planalto.gov.br/ccivil_03/_ato2007-2010/2009/decreto/d6949.htm. Acesso em: 10 maio 2021.

BRASIL. Resolução normativa do Conselho Nacional de Imigração no 95, de 10 de agosto de 2011. Brasília, DF. Disponível em: http://www.normaslegais.com.br/legislacao/resolucaocni95_2011.htm. Acesso em: 15 maio 2021.

BRASIL. Ministério da Justiça e Segurança Pública. Resolução Normativa, $n^{\circ}$ 97. Dispõe sobre a concessão do visto permanente previsto no art. 16 da Lei no 6.815, de 19 de agosto de 1980, a nacionais do Haiti. Imigração Laboral Conselho Nacional de Imigração Obmigra Conare Naturalização Tráfico de Pessoas Legislação Publicações Resoluções 
Normativas, de 12 de janeiro de 2011. Brasília, DF. Disponível em: https://portaldeimigracao.mj.gov.br/pt/component/ k2/item/10498-resolucao-normativa-n-97-de-12-de-janeiro-de-2011. Acesso em: 15 maio 2021.

BRASIL. Lei no 13.445, de 24 de maio de 2017. Institui a Lei de Migração. Brasília, DF: Congresso Nacional, 24 maio 2017. Disponível em: http://www.planalto.gov.br/ccivil_03/_ato2015-2018/2017/lei/l13445.htm. Acesso em: 14 maio 2021.

BRASIL. Ministério da Educação. Instituto Nacional de Estudos e Pesquisas Educacionais Anísio Teixeira - INEP. Censo Escolar da Educação Básica, 2019; 2020. Disponível em: https://www.gov.br/inep/pt-br/acesso-a-informacao/ dados-abertos/microdados/censo-escolar. Acesso em: 20 abr. 2021.

BRASIL. Operação Acolhida. Disponível em: http://aplicacoes.mds.gov.br/snas/painel-interiorizacao/. Acesso em: 6 abr. 2021.

BRASIL. Instituto Brasileiro de Geografia e Estatística. Disponível em: https://cidades.ibge.gov.br/brasil/rs/porto-alegre/ panorama. Acesso em: 23 mar. 2021.

BULLA, Gabriela da Silva; SILVA, Rodrigo Lages e; LUCENA, Júlia de Campos; SILVA, Leandro Paz da. Imigração, refúgio e políticas linguísticas no Brasil: reflexões sobre escola plurilíngue e formação de professores a partir de uma prática educacional com estudantes haitianos. Organon, [S.I.], v. 32, n. 62, p. 1-14, 26 jun. 2017. Universidade Federal do Rio Grande do Sul. DOI: http://dx.doi.org/10.22456/2238-8915.72346.

CAVALCANTI, Leonardo; OLIVEIRA, Antônio Tadeu de; MACÊDO, Marília de; PEREDA, Lorena. Resumo Executivo Imigração e Refúgio no Brasil. A inserção do imigrante, solicitante de refúgio e refugiado no mercado de trabalho formal. Observatório das Migrações Internacionais; Ministério da Justiça e Segurança públicos/Conselho Nacional de Imigração e Coordenação Geral de Imigração Laboral. Brasília, DF: OBMigra, 2018.

CAVALCANTI, Leonardo; OLIVEIRA, Antônio Tadeu de; MACÊDO, Marília. Imigração e Refúgio no Brasil. Relatório Anual 2020. [Série Migrações]. Observatório das Migrações Internacionais; Ministério da Justiça e Segurança Pública/Conselho Nacional de Imigração e Coordenação Geral de Imigração Laboral. Brasília, DF: OBMigra, 2020.

COUTO, Mia. O outro pé da sereia. São Paulo: Companhia das Letras, 2006.

ECO, Umberto. Migrazioni e intolleranza. Milano: La nave di Teseo editore, 2019.

FERNANDES, Duval; FARIA, Andressa Virgínia de. O visto humanitário como resposta ao pedido de refúgio dos haitianos. Revista Brasileira de Estudos de População, [S.I.], v. 34, n. 1, p. 145-161, 23 ago. 2017. Associação Brasileira de Estudos Populacionais. DOI: http://dx.doi.org/10.20947/s0102-3098a0012.

FIGUEREDO, Luiz Orencio; ZANELATTO, João Henrique. Trajetória de migrações no Brasil. Acta Scientiarum. Human and Social Sciences, v. 39, n. 1, p. 77-90, 2017. DOI: https://doi.org/10.4025/actascihumansoc.v39i1.31426.

GARCIA, Cecília. Infância e Diáspora: como sente e como a escola pode receber uma criança imigrante? Portal Aprendiz, 2015. Disponível em: https://bit.ly/2m0I5Ot. Acesso em: 12 maio 2021.

HANDERSON, Joseph. Diáspora. Sentidos sociais e mobilidades haitianas. Horiz. antropol., Porto Alegre, v. 21 , n. 43 , p. 51-78, jun. 2015. Disponível em: http://www.scielo.br/scielo.php?script=sci_arttext\&pi$\mathrm{d}=$ S0104-71832015000100051\&lng=pt\&nrm=iso. Acesso em: 12 maio 2021. DOI: http://dx.doi.org/10.1590/ S0104-7183201500010000.

LIA, Cristine Fortes; RADÜNZ, Roberto. Os processos imigratórios dos séculos XIX e XX: diálogos entre o saber acadêmico e a educação básica. Educar em Revista, [S.I.], n. 61, p. 257-272, set. 2016. São Paulo: FapUNIFESP (SciELO). DOI: http://dx.doi.org/10.1590/0104-4060.46330.

MAGALHÃES, Giovanna Mode. Entre muros e passagens: imigração, refúgio e mobilidades no debate educativo, fragmentos do global ao local. 2019. Tese (Doutorado em Educação) - Universidade de São Paulo, São Paulo, 2019.

MARTUSCELLI, Patrícia Nabuco. A Proteção Brasileira para crianças refugiadas e suas consequências. REMHU, Rev. Interdiscip. Mobil. Hum., Brasília, v. 22, n. 42, p. 281-285, June 2014. Disponível em: http://www.scielo.br/scielo. php?script=sci_arttext\&pid=S1980-85852014000100017\&lng=en\&nrm=iso. Acesso em: 14 maio 2021. DOI: https:// doi.org/10.1590/S1980-85852014000100017.

MUHR, Thomas; AZEVEDO, Mário Luiz Neves de. Relações sul-sul em educação: o programa yo, sí puedo e a cooperação em educação do brics em foco. Revista Ibero-Americana de estudos em educação. Araraquara, v. 14, n. 1, p. 2-30. jan./mar. 2019. [E-ISSN: 1982-5587]. DOI: 10.21723/riaee. V14il.11730.

NASCIMENTO, Maria Letícia; MORAIS, Carolina Grandino Pereira. Sobre migração internacional, crianças pequenas e educação infantil: algumas questões. Zero-a-Seis, Florianópolis, v. 23, n. 43, p. 524-542, jan./jun., 2021. Universidade Federal de Santa Catarina. [ISSN 1980-4512]. Disponível em: https://periodicos.ufsc.br/index.php/zeroseis/article/ view/72858/45635. Acesso em 14 maio 2021. DOI: https://doi.org/10.5007/1980-4512.2021.e72858. 
NORÕES, Katia Cristina. De criança a estrangeira, de estrangeira a criança: mobilização social, agenda política e educação pública no município de São Paulo. 2018. Tese (Doutorado em Educação) - Universidade Estadual de Campinas, Campinas, 2018.

NORÕES, Kátia Cristina. Migração infantil e educação: entre silêncios e urgências no acesso a direitos. Zero-a-Seis, Florianópolis, v. 23, n. 43, p. 420-443, jan./jun., 2021. Universidade Federal de Santa Catarina. [ISSN 1980-4512]. Disponível em: https://periodicos.ufsc.br/index.php/zeroseis/article/view/79134/45628. Acesso em: 6 abr. 2021. DOI: https://doi.org/10.5007/1980-4512.2021.e79134.

PEREIRA, Gustavo de Lima. Direitos humanos e hospitalidade: a proteção internacional para apátridas e refugiados. São Paulo: Editora Atlas, 2014. p. 200.

PEREIRA, Gustavo de Lima. Direitos humanos \& migrações forçadas: introdução ao direito migratório no Brasil e no mundo. Porto Alegre: EdiPUCRS, 2019. p. 120.

PORTO ALEGRE. Prefeitura Municipal de Porto Alegre. Decreto $n^{\circ} 18.815$, de 10 de outubro de 2014. Disponível em: http://www2.portoalegre.rs.gov.br/cgi-bin/nph-brs?s1=000034350.DOCN.\&l=20\&u=/netahtml/sirel/simples. html\&p=1\&r=1\&f=G\&d=atos\&SECT1=TEXT. Acesso em: 6 abr. 2021.

PORTO ALEGRE. Secretaria Municipal de Educação. Disponível em: http://www2.portoalegre.rs.gov.br/smed/default. php?p_secao=537. Acesso em: 23 de mar. 2021a.

PORTO ALEGRE. Secretaria Municipal de Educação. Diagnóstico situacional da rede municipal de educação. Gestão 2021-2024, 2021b. Disponível em: http://lproweb.procempa.com.br/pmpa/prefpoa/cs/usu_doc/rme2.pdf. Acesso em: 13 maio 2021.

RESSTEL, Cizina Célia Fernandes Pereira. Fenômeno migratório. In: Desamparo psíquico nos filhos de dekasseguis no retorno ao Brasil [online]. São Paulo: Editora UNESP, São Paulo: Cultura Acadêmica, 2015, p. 35-52. [ISBN 978-857983-674-9]. SciELO Books. Disponível em: <http://books.scielo.org>. Acesso em: 08 ago. 2020.

SARRIERA, Jorge Castellá; PIZZINATO, Adolfo; MENESES, María Piedad Rangel. Aspectos psicossociais da imigração familiar na grande Porto Alegre. Estudos de Psicologia (Natal), [S.I.], v. 10, n. 1, p. 5-13, abr. 2005. São Paulo: FapUNIFESP (SciELO). DOI: http://dx.doi.org/10.1590/s1413-294x2005000100002.

SILVA, Rodrigo Lages e; BULLA, Gabriela da Silva; LUCENA, Júlia de Campos; SILVA, Leandro Paz da; ARAUJO, Matheus dos Santos. Educação de Jovens e adultos e acolhimento de imigrantes em Porto Alegre, Brasil: um relato de experiência com oficinas em aula plurilíngue. Revista Lusófona de Educação, Portugal, v. 1, n. 42, p. 1-15, out. 2018. [Trimestral].

WALDMAN, Tatiana Chang; BREINTENVIESER, Camila Barrero. Caminhos da participação social na formulação de políticas públicas: infância e migração internacional em São Paulo. Zero-a-Seis, Florianópolis, v. 23, n. 43, p. 627-651, jan./ jun., 2021. Universidade Federal de Santa Catarina. [ISSN 1980-4512]. Disponível em: https://periodicos.ufsc.br/index. php/zeroseis/article/view/73428/45642. Acesso em: 14 maio 2021. DOI: https://doi.org/10.5007/1980-4512.2021.e73428.

WEIß, Anja. Becoming a refugee. A life-course approach to migration under duress. Sociologias, Porto Alegre, v. 20, n. 49, p. 110-141, Dec. 2018. Disponível em: http://www.scielo.br/scielo.php?script=sci_arttext\&pid=S1517-45222018000300110\&lng=en\&nrm=iso. Acesso em: 14 maio 2021. DOI: http://dx.doi. org/10.1590/15174522-02004904.

Data de submissão: 15/05/2021

Data de aceite: $23 / 06 / 2021$ 